INFLAMMATORY BOWEL DISEASE

\title{
Human lymphocyte stimulation with pouchitis flora is greater than with flora from a healthy pouch but is suppressed by metronidazole
}

\author{
A J G Bell, R J Nicholls, A Forbes, H J Ellis, P J Ciclitira
}

Gut 2004;53:1801-1805. doi: 10.1136/gut.2003.026807

See end of article for authors' affiliations

Correspondence to:

Professor P J Ciclitira,

Department of

Gastroenterology, The

Rayne Institute (KCL), 4th

Floor Lambeth Wing, St

Thomas' Hospital, Lambeth

Palace Road, London SE 1

7EH, UK; paul.ciclitira@

kcl.ac.uk

Accepted for publication 26 April 2004
Background/Aims: The gut flora may play an important role in the pathogenesis of inflammatory bowel disease. An ileal reservoir or pouch can be created to replace the excised rectum after proctocolectomy. In patients with ulcerative colitis this is subject to inflammation and termed pouchitis. Using bacteria from patients the authors sought evidence for the presence rather than the identity of a pathogenic species in pouchitis, and for its absence in healthy pouches by the differential effect on lymphocyte proliferation. Methods: An ex vivo cell culture assay was used in which peripheral blood mononuclear cells or lamina propria mononuclear cells were cultured with sterile sonicates of gut flora from patients with or without pouchitis in the presence of antigen presenting cells.

Results: Sonicated pouchitis flora produced a consistent and intense proliferation of the mononuclear cells but that produced by sonicates from healthy pouches was minimal $p=0.012$ or 0.018 , peripheral blood or lamina propria mononuclear cells). Preparation of the sonicates with the antibiotic metronidazole abolished their stimulatory ability $(p=0.005$, peripheral blood mononuclear cells). In separate assays neither direct addition of metronidazole nor of its hydroxy metabolite affected the mononuclear cells' proliferation with alternative stimuli.

Conclusions: These results strongly support a bacterial aetiology for pouchitis.
$\mathrm{T}$ he construction of a neorectum from the distal ileum and its anastomosis to the anus provides restoration of intestinal continuity in patients who have undergone total proctocolectomy. ${ }^{1}$ This ileal neorectum, or pouch, is prone to inflammation which is known as pouchitis and which almost exclusively affects those with a diagnosis of ulcerative colitis (UC) rather than familial adenomatous polyposis. ${ }^{2}$

Evidence suggests a role for bacteria in the pathogenesis of inflammatory bowel disease (IBD)..$^{3-5}$ In animal models both B27 transgenic rats ${ }^{6}$ and knockout mice predisposed to colitis require the presence of bacteria to provoke that colitis. ${ }^{7}$ In human disease, improvement is seen in Crohn's disease when the faecal stream is diverted away from the diseased area. ${ }^{8}$ In addition, there is benefit from manipulation of the flora by using antibiotics ${ }^{9}$ or probiotics in pouchitis ${ }^{10-12}$ and in animal models ${ }^{13}$ although in Crohn's disease the proven efficacy of antibiotics is limited to the specific situations of avoiding postoperative recurrence ${ }^{14}$ and perianal disease. ${ }^{15}$ Despite the findings in experimental colitis, there is little evidence for antibiotic use in UC. ${ }^{16}$

Several candidate species have been investigated as potential aetiological agents. For example, increased numbers of $E$ coli and bacteroides have been found adherent to the mucosa in IBD patients, although moderately raised levels of adherent bacteria in subjects with self-limiting inflammation weaken the case for causation. ${ }^{17}$ Increased concentrations of the same bacteria together with fusobacteria in the neoterminal ileum have been found to correlate with early postoperative relapse in Crohn's disease. ${ }^{18}$ Fusobacterium varium has also been observed within the mucosa of UC patients where it seems to stimulate a species specific antibody. Interestingly, when cultured, the supernatants from the cultures of these human isolates produce ulcers in the colons of mice. ${ }^{19}$

Investigation of bacteria with distinct metabolic traits has revealed that whereas a majority of UC pouches harbour sulphate reducing species, these are absent from familial adenomatous polyposis pouches. ${ }^{20}$ However, the intuitive approach of identifying a specific pathogen by comparing the results of culture in IBD and controls is rendered impractical by the number of species present and the lack of universal survival outside the body. ${ }^{21}$

More indirect methods have been used in attempting to identify a pathogen. Serological studies of excreted and circulating antibacterial antibodies, ${ }^{22}{ }^{23}$ and reactivity of bacterial components with commonly found disease related antibodies such as ANCA in UC ${ }^{24}$ or ASCA in Crohn's disease have implicated $B$ vulgatus $(53 \% \quad v \quad 1 \%$ seroreactivity in controls) and $E$ coli in active UC. These are found among many commensals also stimulating a serological response. The response to commensals suggests these findings may reflect secondary colonisation of lesions rather than the cause. The same interpretation can be made for the identification of bacterial components from lymphoid follicles or gut lesions. ${ }^{21}{ }^{25}$ This argument weakens the otherwise strong case made for Mycobacterium paratuberculosis, a putative pathogen in Crohn's disease, by the recent demonstration of its DNA in $92 \%$ of cases versus $26 \%$ of controls using the most sensitive methods. ${ }^{26}$ DNA fingerprinting using 16S rRNA technology holds more promise than culture ${ }^{27}$ but remains a costly method in terms of time and cannot identify all bacteria present.

Our aim was to show the presence rather than the identity of a pathogen or pathogens in the gut flora of pouchitis sufferers by an ex vivo lymphocyte stimulation assay.
Abbreviations: IBD, inflammatory bowel disease; LPMC, lamina propria mononuclear cells; MTZ, metronidazole; PBMC, peripheral blood mononuclear cells; PDAl, pouch disease activity index; PHA, phytohaemagglutinin; SI, stimulation index; UC, ulcerative colitis; Aut, a sonicate derived from pouch flora of same patient whose LPMC/PBMC are under stimulation; Het, a sonicate derived from pouch flora of a different patient from the one whose LPMC/PBMC are under stimulation; $P$, a sonicate derived from pouch flora of a patient with pouchitis; Non, a sonicate derived from pouch flora of a patient without pouchitis; $M$, a sonicate derived from pouch flora grown in the presence of MTZ 
We tested the hypothesis that lamina propria mononuclear cells (LPMC) and peripheral blood mononuclear cells (PBMC) would proliferate more with a sonicate made from the bacterial flora present in pouchitis than they would with one made from the flora in healthy pouches. Secondly, we tested the hypothesis that the antibiotic metronidazole (MTZ) might prevent the growth of the stimulatory bacteria.

\section{MATERIALS AND METHODS Subjects}

Patients aged 18-70 years who had undergone ileal pouch formation and ileostomy reversal for ulcerative colitis (UC) and under regular follow up at a single centre were recruited by letter followed by a telephone call. Pouchitis was defined as a total score of 7 or more on the pouch disease activity index $(\mathrm{PDAI})^{28}$ in patients with clinical, macroscopic, and histological changes. Exclusion criteria were significant comorbidity leading to increased hazard with extra biopsies such as ischaemic heart disease, chronic airways disease, insulin dependent diabetes mellitus, and current anticoagulant use. The subjects gave written informed consent and the Harrow Research Ethics Committee approved the study. Twenty two patients were recruited. One patient failed to attend. Bacterial contamination of the sterile lymphocyte cultures occurred in three. Thus, data from 18 were analysed ( 10 male, 8 female). The median age range was 38.5 years (range 27-68 years). Median pouch age was 126 months (range 2-266 months) and median PDAI score was 1.75 (range 0-9). One patient had active pouchitis (PDAI score 9) with a history of recurrent episodes and ankylosing spondylitis. The yield of lymphocytes from biopsies was variable but the greater the yield the greater the number of experiments which could be performed. This means that the data for some experiments come from fewer than 18 subjects.

\section{Bacterial sonicate preparation}

Four biopsies were taken via a sterile rigid sigmoidoscope from the lower posterior portion of the pouch. Using sterile forceps each biopsy was immediately smeared onto an agar plate preheated to $37^{\circ} \mathrm{C}$ and kept in an insulated bag. For aerobes, CHB agar (Oxoid, Basingstoke, UK) was used. For anaerobes two plates of fastidious anaerobe agar (E\&O Labs, Bonnybridge, UK) preincubated in the "anaerogen compact" system (Oxoid) were used and immediately replaced in the "anaerogen" system to optimise conditions for anaerobic growth. One of these was impregnated with MTZ at $20 \mu \mathrm{g} / \mathrm{ml}$ (E\&O Labs), equating to reported plasma concentrations. ${ }^{29}$ The fourth biopsy was sent for histological analysis.

The plates were cultured for eight days at $37^{\circ} \mathrm{C}$ in a humidified incubator and in $5 \% \mathrm{CO}_{2}$ for aerobes. Bacteria were harvested in a laminar flow cabinet and transported in HBSS (Gibco, Paisley, UK) on ice. In initial experiments cell yields limited the number of sonicates which could be tested. In view of the effect of metronidazole in pouchitis we anticipated a greater response from anaerobes and concentrated on these. So as not to miss an effect from aerobes, half of the yield from the aerobic plate was added to each of the anaerobic harvests. All colonies growing on any one plate were mixed on harvesting.

Sonication of harvested bacteria was performed for 30 minutes on ice using a W385 sonicator (Heat SystemsUltrasonics Inc, NY, USA) at a $50 \%$ duty cycle on power 3 with $10 \mathrm{mM}$ phenylmethylsulphonyl fluoride (SigmaAldrich, Gillingham, UK) as a protease inhibitor. Electron microscopy revealed $>99.9 \%$ fragmentation of bacteria. After centrifugation at $6000 \mathrm{~g}$ for 15 minutes the supernatant was collected and the pellet discarded. Sterility was achieved by 2600 Gy of gamma irradiation. Protein content was assessed using the Bradford method (BioRad Labs Ltd, Hemel
Hempstead, UK). Sonicates were aliquoted and stored at $-80^{\circ} \mathrm{C}$ until used. Sonicates were designated as autologous or heterologous to indicate their origin as being from the patient whose mononuclear cells were under stimulation or from another patient; as $\mathrm{P}$ to designate that they derived from pouchitis and not non-pouchitis patients who were diagnosed as non; and as $\mathrm{M}$ to designate that they were derived from agar plates with metronidazole rather than without. Pure strains of Bacteroides vulgatus (11154), Bacteroides thetaiotaomicron (10582), Bifidobacterium bifidum (10472) (NTCC, PHLS, London, UK), and Escherichia coli (25922, ATCC, Manassas, VA, USA) were obtained and prepared similarly.

\section{Cell preparation and harvest}

After at least two weeks patients returned for further biopsies and venesection. LPMC: biopsies were collected into HBSSCMF (Gibco) and immediately treated with DTT and EDTA followed by a 14 hour collagenase digestion with DNAase I (Boehringer Ingelheim, Bracknell, UK) in AIM V lymphocyte medium (Gibco). Medium and cells were collected through a cell strainer (Falcon, via Marathon LS, London, UK) and washed before density gradient centrifugation over Ficollpaque plus (Amersham Pharmacia Biotech, St Alban's, UK). PBMC: Ficoll density gradient centrifugation was performed.

Cells were $>95 \%$ viable by trypan blue exclusion. FACS analysis revealed that the CD45+ PBMC were $81 \%$ CD3+ of which $67 \%$ were CD4+ and 14\% CD8+. CD45+ LPMC were $89 \%$ CD3+ (49\% CD4+; $40 \%$ CD8+). To avoid degradation of cell surface ligands further purification was not performed. Antigen presenting cells were PBMC that had been irradiated with 8.6 Gy of gamma irradiation.

\section{Cell culture assays}

Each assay was performed in triplicate in AIM V medium with added Plasmocin antibiotic (Invivogen, Cayla, Toulouse, France) at 1 in 10000 with $5 \times 10^{4}$ LPMC or PBMC and $5 \times 10^{4}$ antigen presenting cells per well in 96 well U-bottomed plates (Falcon). The antibiotic was in routine use in the cell culture laboratory, and should not have influenced results as it acts on synthetic pathways of non-eukaryotes. Where cell yields allowed, all six sonicates were tested: AutM, Aut, HetPM, HetP, HetNonM, and HetNon all at $50 \mu \mathrm{g} / \mathrm{ml}$. As a positive control $0.2 \mu \mathrm{g}$ of phytohaemagglutinin (PHA) was added, and albumin was added in lieu of sonicate as an unstimulated control.

In parallel experiments MTZ and its hydroxy metabolite (kindly donated by Aventis Pharma, Vitry-sur-Seine, France) were added to PHA and $B$ vulgatus cultures at $100 \mu \mathrm{M}$ and $50 \mu \mathrm{M}$, respectively, which equate to reported plasma concentrations. These were to examine the direct effect of MTZ on cell culture, which is debated. They also serve as controls to eliminate possible carry over of MTZ with the bacteria from the culture plates to the cell cultures as the explanation of any effect seen in the sonicate stimulation assays. Precautions were observed to avoid accidental direct contact with PHA. Sonicates were plated on agar to test for sterility. Wells which generated colony forming units overtly or when plated were discarded. Incubation in a humidified incubator at $37^{\circ} \mathrm{C}$ and in $5 \% \mathrm{CO}_{2}$ lasted 96 hours with ${ }^{3} \mathrm{H}$ added at $1 \mu \mathrm{Ci} /$ well for a further 16 hours. ${ }^{3} \mathrm{H}$ incorporation was assessed. Institutional safety guidelines for the handling and disposal of radioactive reagents were adhered to.

Proliferation was recorded as the stimulation index (SI) which is the mean scintillation of the triplicate wells divided by the mean of the three unstimulated wells. An SI $>3$ was taken to represent increased proliferation beyond experimental error.

The Wilcoxon signed rank test was used for comparison of treatment conditions. Significance for a two tailed test was chosen as $\mathrm{p}<0.05$. 


\section{RESULTS}

Comparison of proliferation with bacterial sonicates of different origins

In general, mononuclear cells proliferated little when they were stimulated with sonicates derived from either autologous or heterologous pouch bacteria if that pouch was healthy, nor was there a significant difference between the level of proliferation they each induced $(\mathrm{p}=0.247, \mathrm{n}=12$ PBMC; $\mathrm{p}=0.678, \mathrm{n}=12$ LPMC) (fig lA).

However, in the majority of cases strong proliferation was seen with sonicate derived from pouchitis flora whereas weak proliferation close to baseline was observed with nonpouchitis sonicate. This was in eight patients whose mononuclear cells were tested under both conditions in parallel $(\mathrm{p}=0.012 ;$ PBMC) (fig 1B).
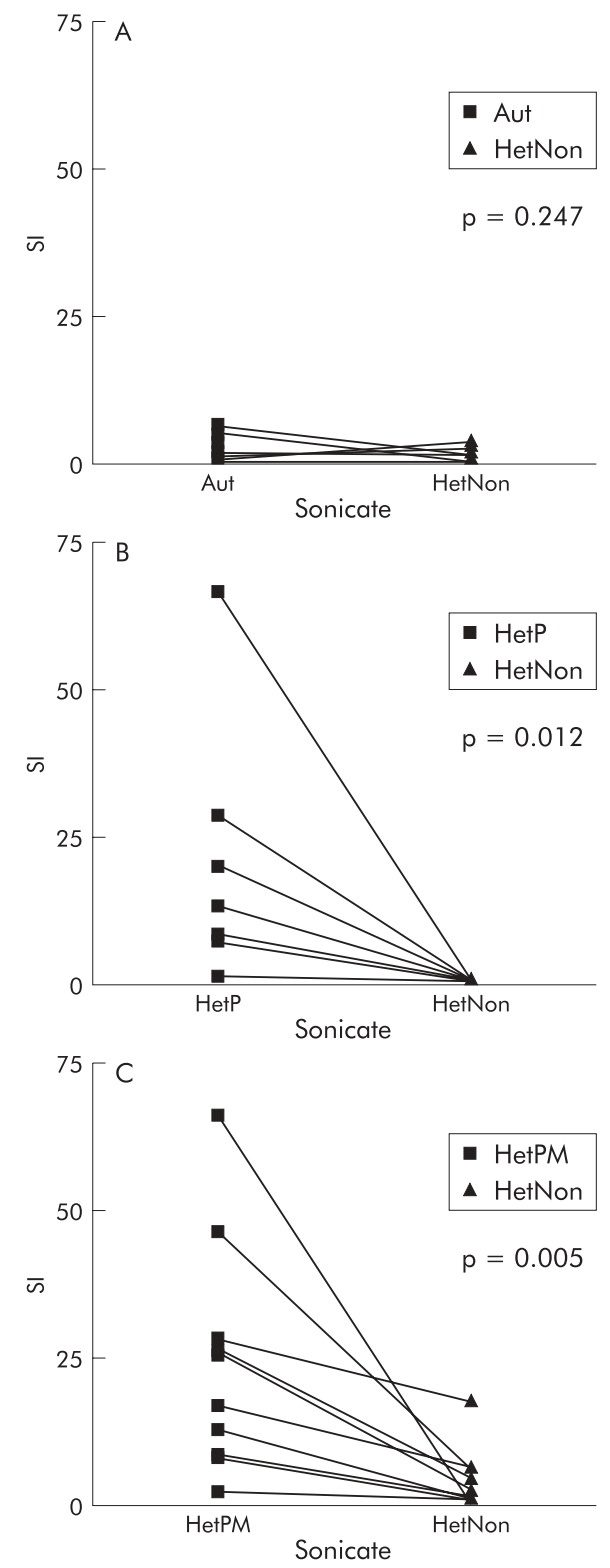

Figure 1 Comparison of proliferation of $\mathrm{PBMC}$ with $(A)$ sonicate of autologous (Aut) or heterologous healthy pouch (HetNon) flora; (B) sonicate of heterologous pouchitis flora (HetP) or heterologous healthy pouch flora (HetNon); (C) sonicate of pouchitis flora grown on agar with metronidazole (HetPM) or without (HetP).
The proliferation was less marked when LPMC were stimulated but was still significantly greater than that provoked by the non-pouchitis sonicate $(p=0.018, n=7)$.

Metronidazole affects proliferation when present at the bacterial culture stage but not when added to the mononuclear cell culture with the sonicate

When pouchitis bacteria were cultured simultaneously in the presence or absence of MTZ the sonicate derived from the MTZ impregnated plate lost the capacity to induce proliferation almost entirely $(\mathrm{p}=0.005, \mathrm{n}=10$; PBMC) (fig $1 \mathrm{C})$. The proliferation was less for LPMC with no significant difference in that provoked between the two types of sonicate $(\mathrm{p}=0.314, \mathrm{n}=10)$.

Proliferation with non-pouchitis sonicate was close to baseline levels regardless of the presence or absence of MTZ in the original agar.

To examine whether MTZ has a profound effect on lymphocyte proliferation, as has been claimed, in a smaller number of parallel experiments MTZ or its hydroxy metabolite were added to PBMC and LPMC cultures together with medium, B vulgatus sonicate or PHA.

For each of the subjects, lymphocyte proliferation with progressively stronger stimuli (medium, then $B$ vulgatus sonicate, then PHA) increased as expected. However, for a given subject under any one of those conditions the addition of MTZ or its hydroxy metabolite made little difference to proliferation. No consistent effect was seen in all subjects under any one condition. This was true for PBMC (fig 2A-C) and LPMC (fig 2D-F).

\section{Mononuclear cell proliferation with other stimuli}

PHA was used as a positive control to confirm viability of the mononuclear cells. The median SI was 560 for PBMC and 177 for LPMC. Sonicate prepared from $E$ coli reduced proliferation below SI of 1 in nearly all cases-that is, below the spontaneous level of proliferation of the mononuclear cells (fig 3A). The same pattern was seen with sonicate from Bifidobacterium bifidum and from Bacteroides thetaiotaomicron in three patients in whom they were tested. In contrast, the sonicate from $B$ vulgatus proved an exceptionally strong stimulus to mononuclear cell proliferation. (fig 3B)

\section{DISCUSSION}

Interaction of the gastrointestinal flora and the gut wall is essential for health. The observation of a specific gut bacterial profile which seems to persist, ${ }^{30} 31$ like a part of one's phenotype, supports the theory that flora probably interact with the host genotype. ${ }^{32}{ }^{33}$ Certain bacteria may interact with certain genotypes to produce disease states: germ free HLA B27 transgenic rats developed severe colitis only when they were exposed to Bacteroides vulgatus. ${ }^{6}$ Therefore, it seems reasonable to propose that some bacterial species or their products interact with hosts with a susceptible genotype to produce mucosal disease.

Given the technological constraints on identifying the different species present in the gut flora and on comparing the total flora of any case and control, we sought to establish the presence of pathogenic species rather than their identity.

Using an ex vivo lymphocyte stimulation assay we examined the flora in pouchitis. We found that bacterial sonicate from a heterologous but healthy pouch, HetNon, did not stimulate lymphocytes (PBMC or LPMC) from patients with healthy pouches. Similarly, there was a seemingly anergic response to sonicate of their own bacteria, Aut (fig 1A). The latter result is consistent with the theory that individuals are tolerant of their own gastrointestinal flora. However, our finding of tolerance to the flora of strangers differs from the findings of Duchmann, ${ }^{34}$ who found a 


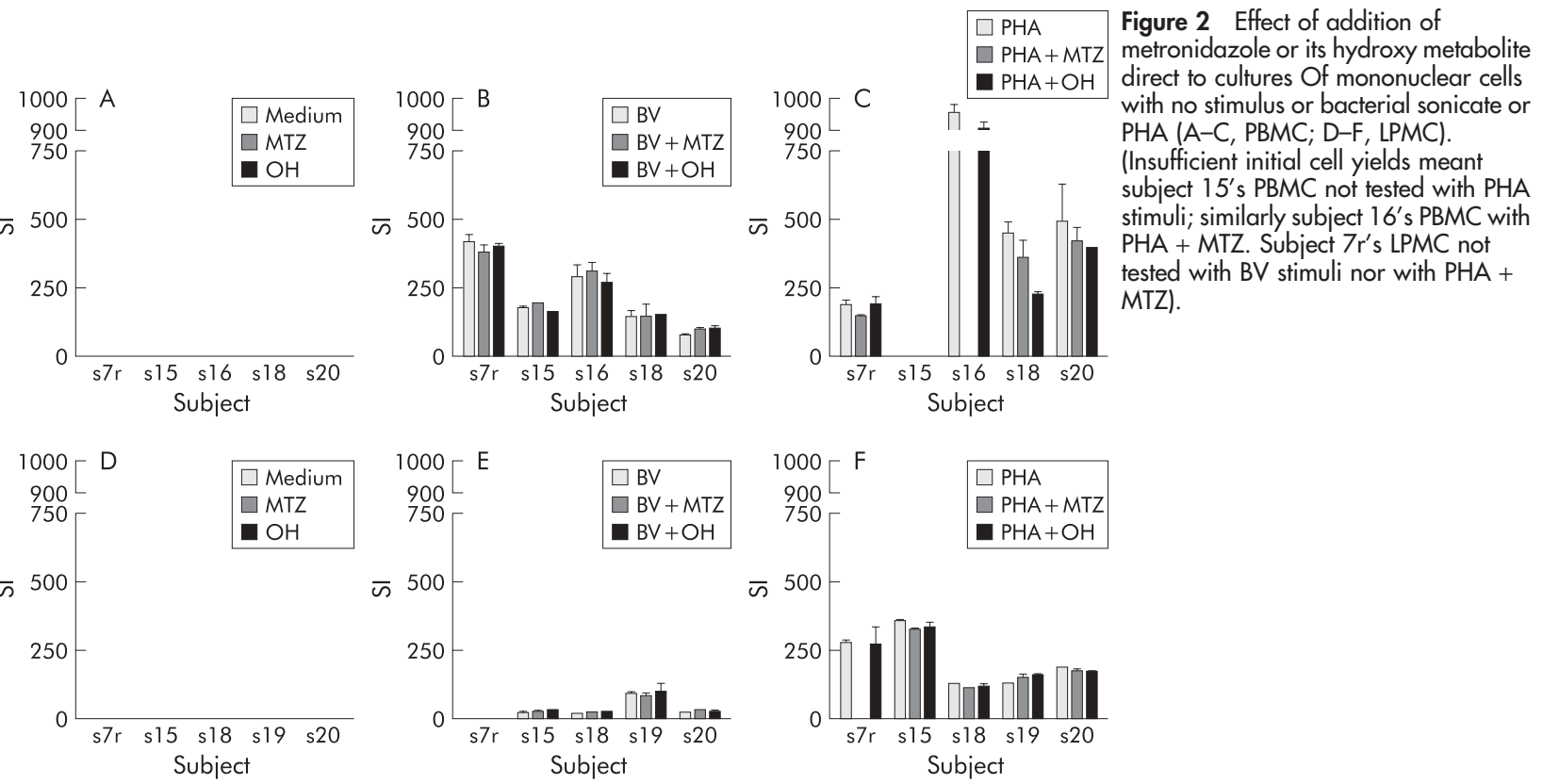

proliferative response to foreign flora. Our use of feeder cells may reflect the mucosal environment more faithfully, as feeder cells (rather than T cells) have been shown to be the main source of the anti-inflammatory cytokine IL-10 when rodent cells are stimulated with commensal bacterial products. ${ }^{35}$ In addition, it is not clear whether their sonicates were derived from inflamed areas. More simply, the explanation may be a dosage effect as their sonicate was 10 times more concentrated than ours.

Our findings with sonicate from inflamed tissue agree with theirs, and this stimulatory effect would be consistent with a more aggressive species being present in a greater predominance in inflamed tissue. The degree of inflammation in the bacterial donor bowel has been found to influence profoundly the stimulatory effect of the sonicate derived from it (Sartor RB, personal communication, 2002). This provides evidence for bacterial pathogenesis of the initial inflammation in that local change to a more pathogenic microflora may initiate activation of the local mononuclear cells. This theory is supported by a recent study showing that lymphocytes respond to the presence of pathogens before active inflammation appears. T cells isolated from mesenteric lymph nodes of $E$ faecalis mono-associated IL-10 knockout mice produced more interferon gamma when pulsed with $E$ faecalis than with $B$ vulgatus. T cells from wild type mice without this exposure did not show the increase. ${ }^{36}$

Our results using other specific sonicates are consistent with other published data regarding intense stimulation with

$B$ vulgatus and inhibition of, or low level proliferation of, LPMC and PBMC with $E$ coli. ${ }^{37} 38$

We have shown that pouchitis derived sonicate (HetP) induces more proliferation in another individual's lymphocytes (PBMC or LPMC) than non-pouchitis derived sonicate (HetNon) (fig 1B). Extraneous factors such as the "cytokine soup", and other host factors in which the bacteria making up the sonicate may have existed before collection, were carefully excluded as colonies were grown from smears of biopsies and were later harvested from the agar. The constituent species of the sonicates was not something we set out to determine. Feasibly, a pathogenic species is present in all pouches but simply in greater number in inflamed ones. However, our examination of the role of the flora in pouches shows that key differences exist and that elements present in pouchitis flora may specifically activate inflammation.

Metronidazole is effective treatment for pouchitis. ${ }^{9}$ Because it has been suggested (although not all would agree ${ }^{39}{ }^{40}$ ) that the action of MTZ might be as an immune modulator, ${ }^{41-43}$ we attempted to separate its effect on lymphocyte stimulation from its effect on the bacteria involved in the stimulation. Thus, the MTZ was introduced in the agar rather than into the cell culture. The concentration was similar to that in serum following oral dosing. A fall to baseline of the lymphocyte proliferation when pouchitis flora were grown on MTZ impregnated medium instead of conventional medium was seen (fig lC).
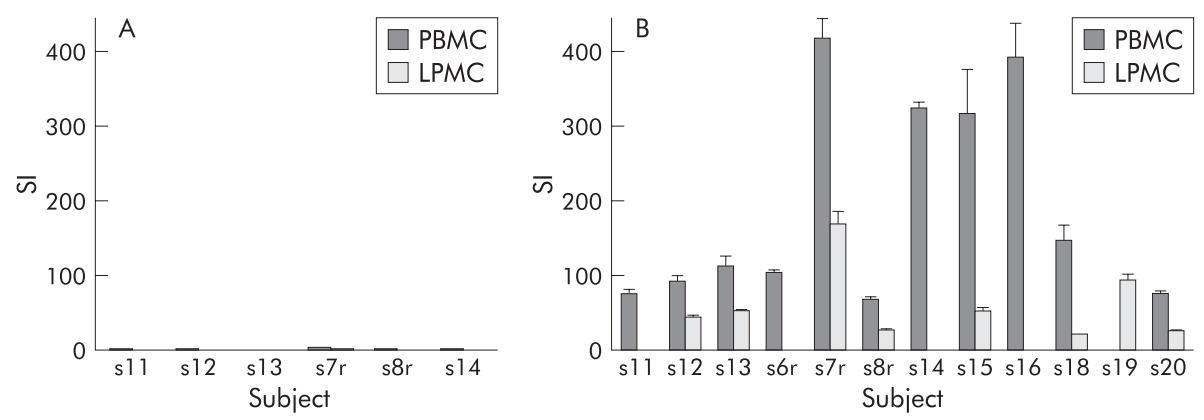

Figure 3 Proliferation by cell type with $E$ coli sonicate $(A)$ and $B$ vulgatus sonicate (B) (where tested). No LPMC were available for subjects $11,6 r, 14$, or 16; no PBMC for 19. 
A smaller number of further assays was conducted to examine the effect of direct addition of MTZ or its main metabolite to cell cultures at a concentration found to exert an inhibitory effect in previous studies. No such reduction in proliferation was seen across assays using, variously, no stimulus, mitogen (PHA), or B vulgatus sonicate (fig $2 \mathrm{~A}-\mathrm{F}$ ). This makes it unlikely that our results reflect carry over of MTZ into cell cultures via incorporation into growing bacteria where it then directly inhibited lymphocyte proliferation. Rather, the organisms responsible for the proliferation appear to be inhibited by the MTZ. This suggests that the reason for the in vivo efficacy of MTZ is its antibacterial action.

The pathogenic species whose presence we propose is shown in our experiment and which are important in the aetiology of pouchitis are, therefore, metronidazole sensitive. MTZ has no action against aerobes or facultative anaerobes. It is active against anaerobes especially $B$ fragilis and other bacteroides and is also bactericidal for fusobacteria, eubacteria, clostridia, and anaerobic cocci. Although it has an antiprotozoal action it is ineffective against mycobacteria.

\section{CONCLUSION}

We have shown that pouchitis derived bacterial sonicate stimulates healthy pouch patients' mononuclear cells significantly more than non-pouchitis derived sonicate. Taking mononuclear cell proliferation as a surrogate marker for inflammation, this makes the eventual demonstration of Koch's third postulate (which stipulates that disease be induced in a suitable host by inoculation with the isolated putative agent) more likely in pouchitis. Moreover, we have shown that the stimulatory species is or are MTZ sensitive.

We believe that this provides strong evidence for a bacterial aetiology in pouchitis. We feel this justifies investing in total 16S rRNA analysis of pouchitis, IBD, and control flora to determine the underlying differences in the microflora composition between healthy and inflamed tissue and, particularly, in the metronidazole sensitive population.

\section{Authors' affiliations}

A J G Bell, R J Nicholls, A Forbes, St Mark's Academic Institute, St Mark's Hospital, Harrow, UK

A J G Bell, H J Ellis, P J Ciclitira, Department of Gastroenterology, The Rayne Institute, St Thomas' Hospital, London, UK

These data were published in abstract form (Gastroenterology 2002;122:A261-2) and were presented orally at the Tripartite Colorectal Conference, Melbourne, 2002.

\section{REFERENCES}

1 Parks AG, Nicholls RJ. Proctocolectomy without ileostomy for ulcerative colitis. BMJ 1978;2:85-8

2 Madden MV, Farthing MJ, Nicholls RJ. Inflammation in ileal reservoirs: 'pouchitis'. Gut 1990;31:247-9.

3 Campieri M, Gionchetti P. Bacteria as the cause of ulcerative colitis. Gut 2001;48:132-5.

4 Cummings JH, Macfarlane GT, Macfarlane S. Intestinal bacteria and ulcerative colitis. Curr Issues Intest Microbiol 2003;4:9-20.

5 Sartor RB. Targeting enteric bacteria in treatment of inflammatory bowel diseases: Why, how, and when. Curr Opin Gastroenterol 2003;19:358-65.

6 Rath HC, Herfarth HH, Ikeda JS, et al. Normal luminal bacteria, especially Bacteroides species, mediate chronic colitis, gastritis, and arthritis in HLA-B27/ human beta2 microglobulin transgenic rats. J Clin Invest 1996;98:945-53.

7 Sellon RK, Tonkonogy S, Schultz M, et al. Resident enteric bacteria are necessary for development of spontaneous colitis and immune system activation in interleukin-10-deficient mice. Infect Immun 1998;66:5224-31.

8 Harper PH, Lee EC, Kettlewell MG, et al. Role of the faecal stream in the maintenance of Crohn's colitis. Gut 1985;26:279-84.

9 Madden MV, Mclntyre AS, Nicholls RJ. Double-blind crossover trial of metronidazole versus placebo in chronic unremitting pouchitis. Dig Dis Sci 1994;39:1193-6.

10 Gionchetti P, Rizzello F, Venturi A, et al. Oral bacteriotherapy as maintenance treatment in patients with chronic pouchitis: a double-blind, placebocontrolled trial. Gastroenterology 2000;119:305-9.

11 Gionchetti P, Rizzello F, Helwig U, et al. Prophylaxis of pouchitis onset with probiotic therapy: a double-blind, placebo-controlled trial. Gastroenterology 2003; 124:1202-9.
12 Mimura T, Rizzello F, Helwig U, et al. Once daily high dose probiotic therapy (VSL\#3) for maintaining remission in recurrent or refractory pouchitis. Gut 2004;53:108-14.

13 Farrell RJ, LaMont JT. Microbial factors in inflammatory bowel disease. Gastroenterol Clin N America 2002;31:41-62.

14 Rutgeerts P, Hiele M, Geboes K, et al. Controlled trial of metronidazole treatment for prevention of Crohn's recurrence after ileal resection. Gastroenterology 1995;108:1617-21.

15 Bernstein LH, Frank MS, Brandt $\sqcup$, et al. Healing of perineal Crohn's disease with metronidazole. Gastroenterology 1980;79:357-65.

16 Casellas F, Borruel N, Papo M, et al. Antiinflammatory effects of enterically coated amoxicillin-clavulanic acid in active ulcerative colitis. Inflamm Bowel Dis 1998:4:1-5.

17 Swidsinski A, Ladhoff A, Pernthaler A, et al. Mucosal flora in inflammatory bowel disease. Gastroenterology 2002;122:44-54.

18 Neut C, Bulois $\mathrm{P}$, Desreumaux $\mathrm{P}$, et al. Changes in the bacterial flora of the neoterminal ileum after ileocolonic resection for Crohn's disease. Am J Gastroenterol 2002;97:939-46.

19 Ohkusa T, Okayasu I, Ogihara T, et al. Induction of experimental ulcerative colitis by Fusobacterium varium isolated from colonic mucosa of patients with ulcerative colitis. Gut 2003;52:79-83.

20 Duffy MP, O'Mahony LP, Coffey JCA, et al. Sulfate-reducing bacteria colonize pouches formed for ulcerative colitis but not for familial adenomatous polyposis. Dis Colon Rectum 2002;45:384-8.

21 Chiba M, Kono M, Hoshina S, et al. Presence of bacterial 16S ribosomal RNA gene segments in human intestinal lymph follicles. Scand J Gastroenterol 2000;35:824-31

22 Macpherson A, Khoo UY, Forgacs I, et al. Mucosal antibodies in inflammatory bowel disease are directed against intestinal bacteria. Gut 1996;38:365-75.

23 Matsuda H, Fujiyama Y, Andoh A, et al. Characterization of antibody responses against rectal mucosa-associated bacterial flora in patients with ulcerative colitis. J Gastroenterol Hepatol 2000;15:61-8.

24 Cohavy O, Bruckner D, Gordon LK, et al. Colonic bacteria express an ulcerative colitis pANCA-related protein epitope. Infect Immun 2000;68:1542-8

25 Liu $Y$, van Kruiningen $H J$, West $A B$, et al. Immunocytochemical evidence of Listeria, Escherichia coli, and Streptococcus antigens in Crohn's disease. Gastroenterology 1995;108:1396-404.

26 Bull TJ, McMinn EJ, Sidi-Boumedine K, et al. Detection and verification of Mycobacterium avium subsp. paratuberculosis in fresh ileocolonic mucosal biopsy specimens from individuals with and without Crohn's disease. J Clin Microbiol 2003:41:2915-23.

27 Relman DA. The search for unrecognized pathogens. Science 1999;284:1308-10.

28 Sandborn WJ, Tremaine WJ, Batts KP, et al. Pouchitis after ileal pouch-anal anastomosis: a Pouchitis Disease Activity Index. Mayo Clin Proc 1994;69:409-15.

29 Reynolds JEF, ed. Martindale-The Extra Pharmacopoeia, 31 st edn. London: Pharmaceutical Press, 1996

30 Bouhnik Y, Pochart P, Marteau P, et al. Fecal recovery in humans of viable Bifidobacterium sp ingested in fermented milk. Gastroenterology 1992; 102:875-8

31 Stebbings S, Munro K, Simon MA, et al. Comparison of the faecal microflora of patients with ankylosing spondylitis and controls using molecular methods of analysis. Rheumatology 2002;41:1395-401.

32 Van De Merwe JP, Stegeman JH, Hazenberg MP. The resident faecal flora is determined by genetic characteristic of the host. Implications for Crohn's disease? Antonie van Leeuwenhoek 1983:49:119-24.

33 Toivanen P, Vaahtovuo J, Eerola E. Influence of major histocompatibility complex on bacterial composition of fecal flora. Infect Immun 2001;69:2372-7.

34 Duchmann R, Kaiser I, Hermann E, et al. Tolerance exists towards resident intestinal flora but is broken in active inflammatory bowel disease (IBD). Clin Exp Immunol 1995;102:448-55.

35 Hoentien F, Tonkonogy SL, Sprengers D, et al. Different cytokine profiles in mesenteric lymph node cells from HLA B27 transgenic versus wild-type rats stimulated with cecal bacterial antigen. Gastroenterology 2001;120:A516.

$36 \mathrm{Kim}$ SC, Tonkonogy SL, Balish E, et al. Bacterial antigen specific T-cell activation precedes intestinal inflammation in Enterococcus faecalis monoassociated IL-10 deficient mice. Gastroenterology 2002;122(Suppl 1):A85-A86

37 Khoo UY, Proctor IE, Macpherson AJ. CD4+ T cell down-regulation in human intestinal mucosa: evidence for intestinal tolerance to luminal bacterial antigens. J Immunol 1997; 158:3626-34.

38 Klapproth JM, Scaletsky IC, McNamara BP, et al. A large toxin from pathogenic Escherichia coli strains that inhibits lymphocyte activation. Infect Immun 2000;68:2148-55

39 Ganrot-Norlin K, Stalhandske T, Karlstrom R. Lack of antiinflammatory activity of metronidazole. Acta Pharmacol Toxicol (Copenh) 1981;49:130-3.

40 Anderson R, Oosthuizen R, Maritz C, et al. Effects of metronidazole on certain functions of human blood neutrophils and lymphocytes. S Afr Med J 1979;55:593-6.

41 Arndt H, Palitzsch K-D, Grisham MB, et al. Metronidazole inhibits leukocyteendothelial cell adhesion in rat mesenteric venules. Gastroenterology 1994; 106:1271-6

42 Elizondo G, Montero R, Herrera JE, et al. Lymphocyte proliferation kinetics and sister-chromatid exchanges in individuals treated with metronidazole. Mutat Res 1994:305:133-7.

43 Grove DI, Mahmound AA, Warren KS. Suppression of cell-mediated immunity by metronidazole. Int Arch Allergy Appl Immunol 1977;54:422-7. 


\section{PostScript}

\section{LETTERS}

\section{ITPA genotyping test does not improve detection of Crohn's disease patients at risk of azathioprine/6-mercaptopurine induced myelosuppression}

The thiopurine drugs azathioprine (AZA) and 6-mercaptopurine (6-MP) are effective for the treatment of inflammatory bowel disease (IBD) and their prescription is increasing. Haematotoxicity, which can lead to potentially life threatening bone marrow suppression, represents the most serious side effect of thiopurine therapy. It has been attributed to the accumulation of active cytotoxic metabolites of AZA/6-MP, collectively called 6-thioguanine nucleotides, resulting from a deficiency in thiopurine catabolism specifically catalysed by the thiopurine $S$-methyltransferase (TPMT) enzyme. Genotyping tests are now available to identify deficient and intermediate methylators who are, respectively, homozygous and heterozygous for non-functional alleles of the TPMT gene. As pointed out by Lennard in the leading article (Gut 2002;51:143-6), it is clear that myelosuppression may be caused by other factors in addition to variable TPMT.

Since the identification of the molecular basis of inosine triphosphate pyrophosphatase (ITPAse) deficiency, ${ }^{1}$ a clinically benign condition characterised by abnormal accumulation of inosine triphosphate in erythrocytes, the possibility of a correlation between thiopurine toxicity and ITPAse deficiency has been raised. Complete ITPase deficiency was found to be associated with a homozygous missense 94C $>$ A mutation that encodes a $\mathrm{Pro}^{32} \mathrm{Thr}$ exchange, whereas an intronic IVS2+21 A $>C$ polymorphism was shown to have a less severe effect, homozygotes retaining $60 \%$ ITPAse activity. It was then postulated that in ITPAse deficient patients treated with thiopurine drugs, a 6-thio-ITP metabolite could accumulate resulting in toxicity. ${ }^{1} \mathrm{~A}$ recent study in 62 patients with inflammatory bowel disease reported a significant association between the ITPA $94 \mathrm{C}>\mathrm{A}$ polymorphism and AZA related adverse effects, specifically flu-like symptoms, rash, and pancreatitis. $^{2}$ No correlation was observed with occurrence of neutropenia but only 11 patients were studied. We previously reported TPMT genotype analysis in 41 Crohn's disease

Table 1 Distribution of ITPA genotypes in 41 Crohn's disease (CD) patients and 100 healthy Caucasians

\begin{tabular}{lcl}
\hline ITPA genotype & CD patients $(n=41)$ & Control populationt $(\mathbf{n}=100)$ \\
\hline$W_{t} / W_{t}$ & $26(0.63)^{*}$ & $64(0.64)$ \\
$W_{t} / 94 C>A$ & $6(0.15)$ & $10(0.10)$ \\
$W_{t} / I V S 2+21 A>C$ & $7(0.17)$ & $24(0.24)$ \\
$94 C>A / 94 C>A$ & $0(0.00)$ & $0(0.00)$ \\
IVS2+21A $>C / I V S 2+21 A>C$ & $1(0.02)$ & $0(0.00)$ \\
$94 C>A / I V S 2+21 A>C$ & $1(0.02)$ & $2(0.02)$ \\
\hline
\end{tabular}

*Values in parentheses represent genotype frequencies.

†The control population comprised 100 healthy Caucasians who were genotyped in a previous study.
(CD) patients who had experienced leucopenia during AZA/6-MP therapy. ${ }^{3}$ Even though this study confirmed the efficiency of TPMT genotyping in identifying patients at risk of developing myelosuppression, it also highlighted its limitations, as only $27 \%$ of patients carried mutant alleles of the TPMT gene that were associated with enzyme deficiency. This prompted us to investigate the occurrence of ITPA mutations in this series of patients in order to evaluate whether genotyping of the ITPAse gene could improve the detection rate of patients at risk of thiopurine myelotoxicity.

Our population comprising $4 \mathrm{l}$ patients with $C D$ has been described in detail previously. ${ }^{3}$ Briefly, all patients had either leucopenia (white blood cell count $<3000$ / $\mathrm{mm}^{3} ; \mathrm{n}=24$ ) or thrombocytopenia (platelets $\left.<100000 / \mathrm{mm}^{3} ; \mathrm{n}=30\right)$, or both $(\mathrm{n}=14)$, leading either to discontinuation of treatment or reduction of dose by $50 \%$ or more during AZA $(\mathrm{n}=33)$ or 6 -MP $(\mathrm{n}=8)$ treatment. Patients were genotyped for the ITPA $94 \mathrm{C}>\mathrm{A}$ and IVS2+21 A $>C$ mutations according to a previously described procedure based on endonuclease digestion of polymerase chain reaction products. ${ }^{1}$ Distribution of the 41 patients according to their ITPA genotype is presented in table 1 and compared with that of a previously published control population of 100 healthy Caucasians. ${ }^{1}$ Allele frequencies in the $\mathrm{CD}$ population were 0.085 for the $94 \mathrm{C}>\mathrm{A}$ mutation and 0.12 for the IVS $2+21 \mathrm{~A}>\mathrm{C}$ mutation, similar to frequencies observed in the control population $(0.06$ and 0.13 , respectively). There was no significant difference in the genotypes distribution between the two populations, which confirmed the lack of association between ITPAse deficiency and myelosuppression during thiopurine therapy. Due to the retrospective nature of the study, no correlation with other side effects could be investigated.

In conclusion, application of ITPA genotyping tests does not seem to improve the identification of patients at risk of myelosuppression with AZA/6-MP therapy. Although we believe that conventional TPMT genotyping tests should still be applied before the initiation of thiopurine treatment, further work is needed on the role of other candidate genes that may be involved in thiopurine haematotoxicity.

\section{Acknowledgements}

We thank $\mathrm{N}$ Ferrari and A Vincent for their assistance in performing the study and the members of the GETAID for recruiting patients in the study.
D Allorge, R Hamdan, F Broly EA2679, Faculté de Médecine/Pôle Recherche, Place de Verdun, Lille, France

C Libersa

Centre d'Investigations Cliniques, Hôpital Cardiologique, CH et U Lille, Lille, France

J-F Colombel

Service d'Hépato-Gastroentérologie, Hôpital Huriez, $\mathrm{CH}$ et $\mathrm{U}$ Lille, Lille, France

Groupe d'Etudes Thérapeutiques des Affections Inflammatoires Digestives (GETAID) Service d'Hépato-Gastroentérologie, Hôpital Saint-Louis, Paris, France

Correspondence to: Professor J-F Colombel, Service d'Hépato-Gastroentérologie, Hôpital Huriez, CH et U Lille, 59037 Lille, France; ifcolombel@chru-lille.fr

doi: $10.1136 /$ gut.2004.055947

Competing Interests: None declared.

\section{References}

1 Sumi S, Marinaki AM, Arenas M, et al. Genetic basis of inosine triphosphate pyrophosphohydrolase deficiency. Hum Genet 2002;111:360-7.

2 Marinaki AM, Ansari A, Duley JA, et al. Adverse drug reactions to azathioprine therapy are associated with polymorphism in the gene encoding inosine triphosphate pyrophosphatase (ITPase). Pharmacogenetics 2004; 14:181-7.

3 Colombel JF, Ferrari N, Debuysere $\mathrm{H}$, et al. Genotypic analysis of thiopurine Smethyltransferase in patients with Crohn's disease and severe myelosuppression during azathioprine therapy. Gastroenterology 2000;118:1025-30.

\section{Small bowel malignancy at diagnosis of coeliac disease}

We were very interested in the paper by Rampertab et al (Gut 2003;52:121-14) and the correspondence by Hawdle et al (Gut 2004;53:470). Their data are quite similar to ours, from the Italian Registry of Complications of Coeliac Disease.

We collected information on 1968 patients over 18 years of age (mean age at diagnosis: 36.7 years; female/male ratio 3:1), diagnosed with coeliac diseases between January 1982 and December 2002 at 20 Italian clinical centres specialised in gastrointestinal disease. The diagnosis was made according to revised ESPGHAN criteria. ${ }^{1}$ We found five $(0.25 \%)$ patients with a small bowel malignancy at the time of diagnosis of coeliac disease. Age range was 49-69 years (mean 59 years) with a predominance of females (4:1). Survival rate was very poor as three patients died within 36 months of diagnosis.

These results indicate that there is an increased risk of developing small bowel malignancy in patients with coeliac disease. This correlation was confirmed by the female/ male ratio. In fact, while small bowel neoplasms are usually more frequent in males, in our population four of five cases were female. Moreover, mean age at diagnosis of these cases was higher than that of patients overall, emphasising that the risk of a neoplasm increases with longstanding coeliac disease. 
In conclusion, early diagnosis of coeliac disease should be made to prevent small bowel neoplasms from developing, and screening for this cancer should be carried out at diagnosis of coeliac disease, especially in patients diagnosed during adulthood.

M Silano, M De Vincenzi

Division of Human Nutrition and Health, Istituto Superiore di Sanità, Rome, Italy

Correspondence to: Dr M Silano, Division of Human Nutrition and Health, Istituto Superiore di Sanita', Viale Regina Elena, 299, 00161 Roma, Italy; marco.silano@iss.it

Competing Interests: None declared.

\section{Reference}

1 Walker-Smith J, Guandalini S, Schmitz J, et al. Revised criteria for diagnosis of coeliac disease. Report of Working Group of European Society of Paediatric Gastroenterology and Nutrition.

J Pediatr Gastroenterol Nutr 1990;65:909-11.

\section{Hypergastrinaemia in patients infected with Helicobacter pylori treated with proton pump inhibitors}

We read with interest the commentary by McColl on Helicobacter pylori infection and long term proton pump inhibitor (PPI) therapy (Gut 2004;53:5-7).

It is remarkable that he did not mention gastrin although hypergastrinaemia is a result of reduced gastric acidity ${ }^{1}$ as well as Helicobacter pylori infection, ${ }^{2}$ and that patients with $H$ pylori infection treated with PPI have additive hypergastrinaemia. ${ }^{3}$ Hypergastrinaemia predisposes to gastric carcinoids in animals $^{45}$ and humans ${ }^{67}$ as well as to malignant ECL cell derived tumours (gastric carcinomas) in animals ${ }^{8}$ and humans. ${ }^{9} 10$

Interestingly, the carcinogenic effect of $H$ pylori infection may be completely explained by its hypergastrinaemic effect, ${ }^{11}$ a work where McColl was one of the authors. Furthermore, the increased gastric cancer frequency in moderate hypergastrinaemic INS-GAS mice concomitantly infected by $H$ pylori infection ${ }^{12}$ may also be caused by increased hypergastrinaemia in infected mice. $^{13}$

To conclude, it is odd that gastrin was not taken into consideration when discussing the risk of gastric cancer following treatment with PPI in patients infected with $H$ pylori. Animal as well as human studies linking gastrin to gastric cancer give support for a strategy where $H$ pylori is eradicated in patients on long term PPI treatment.

\section{H L Waldum}

Correspondence to: Professor H L Waldum, Norwegian University of Science and Technology, Department of Clinical and Molecular Medicine, Trondheim University, Trondheim N-7006, Norway; helge.waldum@medisin.ntnu.no

Competing Interests: None declared.

\section{References}

1 Korman MG, Strickland RG, Hansky J. Serum gastrin in chronic gastritis. BMJ 1971;2:16-18.

2 Moss SF, Calam J. Acid secretion and sensitivity to gastrin in patients with duodenal lulcer: effect of eradication of Helicobacter pylori. Gut 1993;34:888-92
3 Schenk BE, Kuipers EJ, Klinkenberg-Knol EC, et al. Hypergastrinaemia during long-term omeprazole therapy: influences of vagal nerve function, gastric emptying and Helicobacter pylori infection. Aliment Pharmacol Ther

1998; 12:605-12.

4 Havu N. Enterochromaffin-like cell carcinoids of gastric mucosa in rats after life-long inhibition of gastric acid secretion. Digestion

1986;35(suppl):42-55.

5 Hirayama F, Takagi S, Iwao E, et al. Development of poorly differentiated adenocarcinoma and carcinoid due to long-term Helicobacter pylori colonization in Mongolian gerbils. J Gastroenterol 1999;24:450-4.

6 Sjöblom S-M, Sipponen P, Karonen S-L, et al. Argyrophil cell hyperplasia and carcinoid tumours in oxyntic mucosa of the stomach. Dependence on duration of pernicious anaemia. Eur J Gastroenterol Hepatol 1991;31:153-7.

7 Cadiot G, Vissuzaine C, Potet F, et al. Fundic argyrophic carcinoid tumor in a patient with sporadic-type Zollinger-Ellison syndrome. Dig Dis Sci 1995;40:1275-8.

8 Waldum HL, Rørvik H, Falkmer S, et al. Neuroendocrine (ECL-cell) differentiation of spontaneous gastric carcinomas of cotton rats (Sigmodon hispidus). Lab Anim Sci 1999;49:241-7.

9 Qvigstad G, Qvigstad T, Westre B, et al. Neuroendocrine differentiation in gastric adenocarcinomas associated with severe hypergastrinemia and/or pernicious anemia. APMIS 2002;110:132-9.

10 Qvigstad G, Falkmer S, Westre B, et al. Clinical and histopathological tumour progression in $\mathrm{ECL}$ cell carcinoids ("ECLomas"). APMIS 1999;107:1085-93.

11 Hansen S, Vollset SE, Ardill JES, et al. Hypergastrinemia is a strong predictor of distal gastric adenocarcinoma among Helicobacter pylori infected persons. Gastroenterology 1997; 1 12:A575.

12 Wang TC, Dangler CA, Chen D, et al. Synergistic interaction between hypergastrinemia and Helicobacter infection in a mouse model of gastrin carcinoma. Gastroenterology 2000; 1 18:36-47.

13 Waldum HL, Brenna E, Martinsen TC. Safety of proton pump inhibitors. Aliment Pharmacol Ther 2000; 14:1537-8.

\section{Terminal ileal biopsies should not} be used to document extent of colonoscopic examination

We commend the British Society of Gastroenterology and the authors for the excellent publication of guidelines for the management of inflammatory bowel disease in adults (Gut 2004;53(suppl V):vi-16). However, we feel that their recommendation for routine terminal ileal biopsying is inappropriate. Although it is important to biopsy the terminal ileum if there is macroscopic evidence of an abnormality, their statement that "a terminal ileal biopsy performed at colonoscopy documents the extent of examination" is not recommended practice, due to the potential risk of variant Creutzfeld-Jacob disease transmission from prion proteins which are prevalent in the lymphoid tissue of Peyer's patches in the ileum. Although the use of disposable forceps may reduce the risk of transmission, there could still be contamination of the intubation channel of the colonoscope and prion protein is resistant to the standard endoscopic cleaning process. ${ }^{1}$ If the extent of examination needs to be documented, then a photograph of the ileocaecal valve or ileal mucosa is preferable.

It is worth emphasising that prion protein may be present in any part of the gastrointestinal tract $^{2}$ and random biopsy of gastrointestinal mucosa for reasons other than confirming an endoscopic abnormality or excluding microscopic colitis is not accepta- ble. Similarly, for surveillance colonoscopy where multiple biopsy is recommended, the risk benefit ratio of this policy must be supported by the clinical indications.

M D Rutter

University Hospital of North Tees, Stockton-on-Tees, Cleveland, UK

M G Bramble

James Cook University Hospital, Middlesbrough, Cleveland, UK

Correspondence to: Dr M D Rutter, University Hospital of North Tees, Stockton-on-Tees, Cleveland, TS19 8PE, UK; matt.rutter@nth.nhs.uk

Competing Interests: None declared.

\section{References}

1 Bramble MG, Ironside JW. Creutzfeld-Jakob disease: implications for gastroenterology. Gut 2002;50:888-90.

2 Herzog C, Sales N, Etchegaray N, et al. Tissue distribution of bovine spongiform encephalopathy agent in primates after intravenous or oral infection. Lancet 2004;363:422-8.

\section{$\lg G$ food antibodies should be studied in similarly treated groups}

The recent paper by Atkinson and colleagues (Gut 2004;53:1459-1464) regarding IgG food antibodies and irritable bowel syndrome (IBS) fails to compare like with like. Regardless of the IgG results, the treatment group excluded significantly different foods to the control group, particularly those foods which appear to exacerbate symptoms of IBS. Of particular concern is the "yeast exclusion" diet. A low yeast diet is not a recognised diet in standard textbooks of dietetics and nutrition. However, alternative practitioners offering such a "yeast exclusion diet" sometimes recommend exclusion of a wide range of foods, such as: bakery products, alcoholic beverages, many other beverages including commercial fruit juices, cereals, condiments, dairy produce, fungi, meat products (hamburgers, sausages, and cooked meats made with bread or breadcrumbs), yeast extracts (Bisto, Marmite, Oxo, Bovril, Vegemite, gravy browning, and all similar extracts), all B vitamin preparations, and sometimes, most worryingly, "sugar foods" (sugar, sucrose, fructose, maltose, lactose, glycogen, glucose milk, sweets, chocolate, sweet biscuits, cakes, candies, cookies, puddings, desserts, canned food, packaged food, hamburgers, honey, mannitol, sorbitol, galactose, monosaccharides, polysaccharides, date sugar, turbinado sugar, molasses, maple syrup, most bottled juices, all soft drinks, tonic water, milkshakes, raisins, dried apricots, dates, prunes, dried figs, and other dried fruit).

Therefore, regardless of IgG antibody status, the dietary restrictions in one group are not controlled for by the other group, and hence the conclusion may not be valid.

It would also be helpful to know if any of the patients with IgG antibodies to a particular antigen also had IgE antibodies to the same antigen.

W A C Sewell

Correspondence to: Dr W A C Sewell, Path Links Immunology, Scunthorpe General Hospital, Scunthorpe DN15 7BH, UK; carrock.sewell@nlg.nhs.uk

Competing Interests: None declared. 


\section{IgG antibodies to foods in IBS}

We read with interest the article by Atkinson et al (Gut 2004;53:1459-64). The authors describe an important advance in our understanding of the putative role of inflammation in irritable bowel syndrome (IBS). However, we wonder whether their conclusion that assay of IgG antibodies may have a role in identifying candidate foods for elimination to treat patients with IBS may be a step too far. The four foods to which the patients most commonly formed antibodies and hence the four foods most commonly eliminated from the "true diet" were yeast $(86.7 \%)$, milk $(84.3 \%)$, whole egg $(58.3 \%)$, and wheat (49.3\%). The "sham diet" involved eliminating foods to which the patients had not formed antibodies and, therefore, in the sham group the exclusion rates for yeast, milk, whole egg, and wheat were very low $(0 \%, 1.3 \%, 26.7 \%$, and $8 \%$ respectively). It is therefore difficult to assess whether a diet excluding these foods would have led to symptomatic improvement in all patients, regardless of their antibody status.

Furthermore, the foods to which the study group commonly formed antibodies were similar to those already identified as leading to symptomatic benefit in patients with IBS when excluded from their diet. In a review cited by Atkinson and colleagues, ${ }^{1}$ it was noted that in eight trials of exclusion diets in IBS, seven identified dairy products and five identified wheat as worsening symptoms. It is not clear whether the difference in improvement in symptoms seen in the current study between true and sham groups can be explained simply by the omission of these foods. This could in practice eliminate the need for antibody testing.

J E D Mawdsley, P Irving, R Makins Barts and the London School of Medicine and Dentistry, London, UK

Correspondence to: Dr J E D Mawdsley, St Bartholomew's and Royal London Hospital, Turner St, London El 2AD, UK; joelmawdsley@yahoo.com

Competing Interests: None declared.

\section{Reference}

1 Burden S. Dietary treatment of irritable bowel syndrome: current evidence and guidelines for future practice. J Hum Nutr Diet 2001; 14:231-41.

\section{Influence of dietary factors on the clinical course of inflammatory bowel disease}

Jowett et al reported in their elegant study on the role of diet in maintaining remission in patients with ulcerative colitis (Gut 2004;53:1479-84). Surely the effect of diet has an essential, but often forgotten, role in altering the course of disease in all types of inflammatory bowel diseases. This role does not necessarily act by maintaining patients in remission clinically, but perhaps more importantly by minimising the activities of the disease and rendering it quiescent.

We have recently reported a case of active stricturing Crohn's disease in an adult female patient with high stoma output. ${ }^{1}$ She was treated solely with casein base formula (Modulen IBD-Nestle, Vevey, Switzerland) for three weeks. Her stoma output was reduced from $2800 \mathrm{ml}$ to $400 \mathrm{ml}$ per day by day 10. Serum albumin and serum protein significantly increased also. She subjectively felt better and pain free and stopped her opiate and non- opiate formula. The casein based formula is a nutritionally complete formulation containing a natural antiinflammatory growth factor, transforming growth factor $\alpha 2$. The mechanism for inducing remission in our patient was possibly inhibition of expression of MHC class II protein in downregulating the inflammatory response. ${ }^{2}$

Previous studies have shown that there is a decrease in plasma antioxidant defences in all types of inflammatory bowel disease. ${ }^{3}$ This is mirrored by an increase in free radical peripheral leucocyte DNA damage. It is therefore possible that the casein based formula acts as an antioxidant to minimise the oxidative stress that occurs in patients with active Crohn's disease. Another possible mechanism is that this formula may have a role as a prebiotic by stimulating the activity of bacteria which are already present in the gut.

Remission induced in our case study highlights the part played by a casein based formula in the management of adult Crohn's disease. The encouraging result demonstrates the need to treat similar cases with dietary measures first. This opportunity should not be missed as it may well obviate the need for surgical intervention or administration of potent pharmacotherapeutic agents which carries the risk of several comorbidities.

N Y Haboubi, $S$ Jones

Nevill Hall Hospital, Gwent, South Wales, UK

Correspondence to: $\operatorname{Dr} N$ Y Haboubi, Nevill Hall Hospital, Brecon Rd, Abergavenny, Gwent NP7 7EG, South Wales, UK; nadim.haboubi@ gwent.wales.nhs.uk

Competing Interests: None declared.

\section{References}

1 Jones S, Shannon H, Srivastava E, et al. A novel approach to a patient with Crohn's disease and a high stoma output: a missed opportunity? Scand J Gastroenterol 2004;4:398-400.

2 Donnet-Hughes A, Duc N, Serrant P, et al. Bioactive molecules in milk and their role in health and disease: the role of transforming growth factor- $\alpha$. Immunol Cell Biol 2000:34:49-53.

3 D'Odorico A, BortolanS, Gaardin R, et al. Reduced plasma antioxidant concentrations and increased oxidative DNA damage in inflammatory bowel disease.

Scand J Gastroenterol 2001;36:1289-94.

\section{Identification of ferroportin disease in the Indian subcontinent}

Haemochromatosis is a common inherited disorder of iron metabolism, characterised by excessive iron absorption and deposition in tissues. The majority of cases are associated with mutations in the HFE gene and inherited in an autosomal recessive manner.' Autosomal dominant forms of haemochromatosis have been reported, mainly associated with mutations in the ferroportin 1 gene. ${ }^{2}$ This syndrome, termed type 4 haemochromatosis or more recently ferroportin disease, ${ }^{3}$ is usually characterised by an early increase in serum ferritin with normal transferrin saturation. Iron accumulation is most prominent in Kupffer cells and other macrophages, in addition to hepatocytes. Some patients do not tolerate venesection therapy well and can develop anaemia. Hereditary iron overload disorders appear to be uncommon in Asia. Secondary iron overload due to beta thalassaemia is relatively common in the Indian subcontinent. However, primary iron overload disorders and HFE mutations appear to be rare and cases have not been well characterised in this region. ${ }^{45}$ We identified a patient from the Indian subcontinent with features typical of ferroportin disease.

A 36 year old female of Sri Lankan origin presented for a routine medical examination in December 2003. She was found to have an elevated serum ferritin of $3145 \mu \mathrm{g} / \mathrm{l}$. Her serum iron $(17.1 \mu \mathrm{mol} / \mathrm{l})$ and transferrin saturation $(29 \%)$ were normal. Liver functions tests, blood glucose, and thyroid studies were all normal. Physical examination was normal and she had no significant past medical history or risk factors for iron overload.

C282Y, H63D, and S65C HFE gene mutations were all negative and she had no family history of iron overload. Her mother and three siblings all had normal serum ferritin levels. Her father died of ischaemic heart disease aged 48 years.

A magnetic resonance imaging scan showed hepatic iron overload. Liver biopsy showed grade 3-4 iron deposition within hepatocytes and Kupffer cells; no fibrosis or cirrhosis was evident (fig 1). The hepatic iron concentration was $17700 \mu \mathrm{g} / \mathrm{g}$ dry weight and hepatic iron index was 9.1.

Venesection therapy was initially poorly tolerated with the development of anaemia following the first two $500 \mathrm{ml}$ venesections. Her haemoglobin is now stable on a programme of $300-500 \mathrm{ml}$ venesections every three weeks.

The features of ferroportin disease in this patient led us to sequence the ferroportin 1 gene, as previously described. ${ }^{6}$ Analysis of the DNA sequence revealed a heterozygous three base pair deletion (TTG) in exon 5. This is the same deletion, Vl62del, described by us and others in haemochromatosis patients from Australia, the UK, Italy, and Greece..$^{6-9}$

This is the first report to identify Vl62del or indeed any ferroportin 1 mutation in an individual from the Indian subcontinent. Identification of V162del in an Asian patient confirms that this mutation is likely to be the most common mutation of ferroportin 1 and the most common cause of non-HFE associated haemochromatosis. The wide geographical distribution of this mutation suggests that it is a recurrent mutation that has repeatedly arisen in distinct populations, probably by slippage mispairing.

Iron overload in this patient was typical of ferroportin disease. At the time of diagnosis she was asymptomatic and had no fibrosis on liver biopsy. Whether fibrosis or clinical complications will develop with age if iron stores are not depleted is unclear.

In conclusion, we have identified the V162del mutation of ferroportin 1 in a fifth geographical location, emphasising that this mutation is the most common and widely distributed mutation which causes non-HFE haemochromatosis. We have identified V162del in a region where iron overload disorders have not been well characterised. Analysis of this and other ferroportin 1 mutations may be useful in the study of iron overload disorders in this region and may be the basis of hitherto unexplained cases of iron overload. 

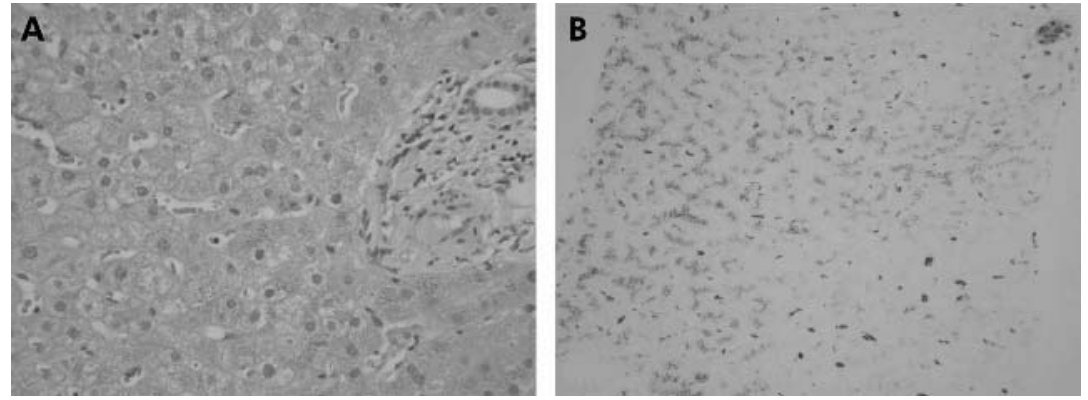

Figure 1 Liver biopsy sections from our patient stained with (A) haematoxylin and eosin and (B) Perls' Prussian blue (magnification 100×). Grade 3-4 iron is prominent in hepatocytes and Kupffer cells.

\section{Acknowledgements}

This work was supported in part by grants from the National Health and Medical Research Council of Australia (953219), the National Institutes of Health, USA (5R01DK057648-02), and the Haemochromatosis Society of Australia to VNS.

D F Wallace

Membrane Transport Laboratory, The Queensland Institute of Medical Research, Brisbane, Queensland, Australia

P Browett

Department of Molecular Medicine and Pathology, University of Auckland, and LabPlus, Auckland City Hospital, Auckland, New Zealand

P Wong

Department of Gastroenterology, Auckland City Hospital, Auckland, New Zealand

H Kua

Diagnostic Medlab, Auckland, New Zealand

R Ameratunga

LabPlus, Auckland City Hospital, Auckland, New Zealand

V N Subramaniam Membrane Transport Laboratory, the Queensland Institute of Medical Research, Brisbane, Queensland,

Australia

Correspondence to: Dr V N Subramaniam, Membrane Transport Laboratory, The Queensland Institute of Medical Research, 300 Herston Rd Herston, Brisbane, QLD 4006, Australia; nathanS@ qimr.edu.au

doi: 10.1136/gut.2004.060988

Competing Interests: None declared.

\section{References}

1 Feder JN, Gnirke A, Thomas W, et al. A novel MHC class I-like gene is mutated in patients with hereditary haemochromatosis. Nat Genet 1996:13:399-408.

2 Pietrangelo A. Non-HFE hemochromatosis. Hepatology 2004;39:21-9.

3 Pietrangelo A. The ferroportin disease. Blood Cells Mol Dis 2004;32:131-8.

4 Kaur G, Rapthap CC, Xavier M, et al. Distribution of C282Y and H63D mutations in the HFE gene in healthy Asian Indians and patients with thalassaemia major. Natl Med J India 2003:16:309-10.

5 Thakur V, Guptan RC, Hashmi AZ, et al. Absence of hemochromatosis associated Cys282Tyr HFE chronic liver disease patients in India. J Gastroenterol Hepatol 2004; 19:86-90.

6 Wallace DF, Pedersen P, Dixon JL, et al. Novel mutation in ferroportin 1 is associated with autosomal dominant hemochromatosis. Blood 2002; 100:692-4

7 Devalia V, Carter K, Walker AP, et al. Autosomal dominant reticuloendothelial iron overload associated with a 3-base pair deletion in the ferroportin 1 gene (SLC11A3). Blood 2002; 100:695-7.

8 Roetto A, Merryweather-Clarke AT, Daraio F, et al. A valine deletion of ferroportin 1: a common mutation in hemochromastosis type 4 . Blood 2002;100:733-4.

9 Cazzola M, Cremonesi L, Papaioannou M, et al. Genetic hyperferritinaemia and reticuloendothelial iron overload associated with a three base pair deletion in the coding region of the ferroportin gene (SLC 1 1A3). Br J Haematol 2002;119:539-46.

\section{BOOK REVIEW}

\section{Morson and Dawson's Gastrointestinal Pathology, 4th edn}

Edited by D W Day, J R Jass, A B Price, et al. $£ 175.00$, pp 692. ISBN 0-632-04204-4

Why do people buy s book such as this, which involves a not inconsiderable financial outlay (even if you box clever and make it tax firstly, for use as a bench book, and secondly, for information on the pathological basis of gastrointestinal disease for interest, teaching, or indeed research purposes.

On the first criterion, this book succeeds, usually quite brilliantly. As a vade mecum on gastrointestinal pathology it should be on the shelf of every pathologist who engages in the reporting of such material. In my view, the book is more user friendly than the gene mutation and low frequency of hemochromatosis phenotype in nonalcoholic Massachusetts: Blackwell Publishing, 2003, deductible)? I think for two main reasons-
competition-Fenoglio-Preiser and Goldman to name but two-and is certainly more readable. I would therefore extol its virtues unreservedly in this respect.

On the second criterion, as a source book, I suppose the correct word is patchy. Some sections, for example that on colorectal tumours, is admirable in this respect, whereas other sections are more limited in scope and even cursory in their treatment of the pathobiology. There is also the problem of the unavoidable intrinsic delay in producing such a book, resulting in reference lists which are some years away from the publication date. I am aware however that my personal outlook is not that of most individuals who will purchase this volume so I am probably being over critical. It is, after all, quintessentially a bench book, and excellent at that.

However, I do have one real beef. In any multiauthor work there is bound to be variation, but here we are not told which one of the stellar caste were responsible for which section or chapter. Of course we can make informed guesses about the Barrett's or colorectal carcinoma sections, but who did the GIST bit? Because of some (minor) errors in the criteria for the diagnosis of malignancy, I have tried to berate a number of authors who have all denied responsibility, and blamed someone else-usually the author(s) absent at the time. Not good enough.

I have to concede however that the authors have succeeded in producing perhaps the text in gastrointestinal pathology, which is a credit to both themselves and the discipline in the UK. I congratulate them.

N A Wright

\section{CORRECTIONS}

doi: 10.1136/gut.2003.025494corr 1

In the January 2005 issue of Gut, one of the author's names of the paper entitled Human peripheral and gastric lymphocyte responses to Helicobacter pylori NapA and AphC differ in infected and uninfected individuals $(\mathrm{H} \mathrm{J}$ Windle, Y S Ang, V A Morales, R McManus, and D Kelleher. Gut 2005;54:25-32) was cited incorrectly. V A Morales should read V AthieMorales. The journal apologises for this mistake.

\section{doi: 10.1136/gut.2003.026807corr 1}

In the December issue of Gut fig 1 in the paper by AJG Bell et al (Human lymphocyte stimulation with pouchitis flora is greater than with flora from a healthy pouch but is suppressed by metronidazole. Gut 2004;53: 1801-1805) is incorrect. The labels for fig $1 \mathrm{C}$ are inverted; the squares should have been labelled HetNon and the triangles HetPM. The legend is also incorrect because the label for flora grown on agar without metronidazole is HetNon, not HetP as stated. 